Dikirim: 26 September 2016 Diterbitkan: 1 Februari 2017

\section{Pengaruh konseling laktasi terhadap pengetahuan kemampuan dan keberhasilan ibu dalam pemberian ASI}

The effect of lactation counseling towards mother's knowledge, ability and success rate in breastfeeding

Anita Liliana ${ }^{1}$, Wenny Artanti Nisman ${ }^{1}$, Elsi Dwi Hapsari ${ }^{1}$

Abstract

Purpose: This study aimed to identify the effect of lactation counseling towards mother's knowledge, ability, and success in breastfeeding in Panembahan Senopati General Hospital, Bantul. Methods: This research was a quasi-experimental study with a post test-only non-equivalent control group design. Sample collection technique used consecutive sampling with 32 respondents as total samples in each group (intervention group and control group). Results: Bivariate analysis used chi square tests with significance level $p<0.05$. The intervention group was given lactation counseling $(p=0.000[<0.05])$. There was a significant difference in mother's ability to breastfeed between the intervention group and control group after they were given lactation counseling ( $p=0.012[<0.05]$; $R R=1.917)$. There was also a significant difference in the success rate of breastfeeding between the intervention and control group after counseling ( $p=0.006[<0.05] ; \mathrm{RR}=2.500)$. Conclusion: Lactation counseling can positively affect the mother's knowledge, ability, and success rate in breastfeeding.

Keywords: counseling; lactation; breastfeeding

\footnotetext{
${ }^{1}$ Program Studi Ilmu Keperawatan, Fakultas Kedokteran, Universitas Gadjah Mada

(Email: lilianaanita36@yahoo.com)
} 


\section{PENDAHULUAN}

Pemberian Air Susu Ibu (ASI) eksklusif khususnya 6 bulan pertama terbukti mampu mengurangi dampak risiko kematian bayi. ASI merupakan makanan terbaik untuk bayi karena mengandung semua zat gizi penting untuk kebutuhan bayi. Pemberian ASI eksklusif di negara berkembang mampu menurunkan angka kematian bayi dengan menurunkan penyakit diare dan infeksi lain. Inisiasi Menyusu Dini (IMD) dan ASI eksklusif berturut dapat mengurangi 22\% dan 13\% kematian neonatus (1). Cakupan pemberian ASI eksklusif pada bayi usia 0 sampai 6 bulan di Indonesia tahun 2012 masih cukup rendah, sebesar 42\%, dengan target pencapaian pemberian ASI eksklusif tahun 2014 sebesar $80 \%$ (2). Salah satu penyebab cakupan pemberian ASI eksklusif rendah bagi bayi di bawah usia enam bulan karena produksi ASI ibu post partum yang terhambat pada hari-hari pertama pasca persalinan, sehingga sebagian besar bayi mendapatkan susu formula pada saat baru lahir (3).

Program pemberian ASI Eksklusif di provinsi Daerah Istimewa Yogyakarta (DIY) merupakan salah satu program yang cukup sulit dikembangkan karena berkaitan dengan berbagai permasalahan sosial di masyarakat. Cakupan ASI ekslusif di provinsi DIY pada tahun 2008 baru mencapai 39,9\%, pada tahun 2009 menurun menjadi 34,56\%, sedangkan pada tahun 2010, cakupan ASI Eksklusif meningkat mencapai 40,57\% namun belum mencapai target Departemen Kesehatan. Cakupan ASI Eksklusif di empat kabupaten yaitu Sleman, Bantul, Kulon Progo, Gunungkidul, dan kota Yogyakarta masih berkisar 20 $39 \%$ (4).

Pengetahuan tentang ASI dan kesadaran akan kesehatan ibu dan anak di kalangan masyarakat Bantul dirasa masih kurang. Terlihat dari angka kematian bayi sebesar 12/1000 kelahiran hidup 2005 dan 9,8/1000 kelahiran hidup di tahun 2006, serta capaian ASI eksklusif di bawah 30\%. Oleh sebab itu, kesadaran atas pemenuhan hak anak dan pengetahuan kesehatan ibu dan anak perlu menjadi perhatian (5).

Pengalaman menunjukkan bahwa peran tenaga konselor menyusui penting terhadap peningkatan pemberdayaan ibu, peningkatan dukungan anggota keluarga serta peningkatan kualitas layanan kesehatan yang berdampak pada peningkatan cakupan ASI eksklusif di Indonesia. Oleh karena itu, keberadaan tenaga konselor menyusui perlu dipertahankan dan ditingkatkan (6).

Berdasarkan kurangnya pengetahuan dan kesadaran ibu tentang ASI dan kaitannya dengan konseling, penelitian ini penting untuk dilakukan.
Penelitian ini dilakukan dengan tujuan untuk mengidentifikasi pengaruh konseling laktasi terhadap pengetahuan, kemampuan dan keberhasilan ibu dalam pemberian ASI di RSUD Panembahan Senopati Bantul.

\section{METODE}

Penelitian quasi exsperiment dilakukan menggunakan posttest only nonequivalent control group. Populasi target dalam penelitian adalah ibu hamil trimester III yang sedang melakukan pemeriksaan kehamilan di poli kandungan RSUD Panembahan Senopati Bantul sesuai dengan kriteria kelayakan. Sampel penelitian berjumlah 64 responden yang terdiri dari 32 responden kelompok intervensi yang diberikan konseling laktasi, dan 32 responden kelompok kontrol yang tidak diberikan konseling laktasi. Pengambilan sampel dari populasi yang ada dilakukan dengan consecutive sampling. Analisis data menggunakan uji Chi-square dengan tingkat kemaknaan $p<0,05$.

Variabel bebas dalam penelitian ini adalah konseling laktasi. Variabel terikat adalah pengetahuan, kemampuan dan keberhasilan ibu dalam pemberian ASI dan variabel luar adalah IMD, usia, pendidikan, status pekerjaan, paritas, dukungan pasangan, frekuensi menyusui dan rawat gabung.

Instrumen pengumpulan data untuk pengetahuan dan keberhasilan pemberian ASI menggunakan lembar kuesioner dan untuk kemampuan menggunakan lembar observasi pengamatan menyusui dari modul konseling 40 jam dari WHO .

\section{HASIL}

Tabel 1 menunjukkan bahwa usia ibu, paritas, pekerjaan, pendidikan, IMD, keberhasilan menyusui, frekuensi menyusui, waktu rawat gabung dan dukungan suami pada kedua kelompok homogen dengan p-value $>0,05$. Adapun hasil pada kedua kelompok didapatkan tidak ada perbedaan pengetahuan yang signifikan antara kelompok intervensi dengan kelompok kontrol sebelum diberikan konseling laktasi ( $p$-value 0,762>0,05).

Sebagian besar responden diketahui berusia 20-34 tahun, paritas multipara, tidak bekerja, berpendidikan tinggi, tergolong gagal pada inisiasi menyusui dini, rawat gabung > 24 jam, frekuensi menyusui tergolong sering, mendapatkan dukungan suami terkait pemberian ASI ekslusif, serta memiliki pengetahuan ASI eksklusif yang rendah sebelum pemberian konseling. Rincian karakteristik responden dan uji homogenitas 
antar kelompok dapat dilihat pada Tabel 1 sebagai berikut.

Tabel 1. Karakteristik responden dan uji homogenitas antar kelompok

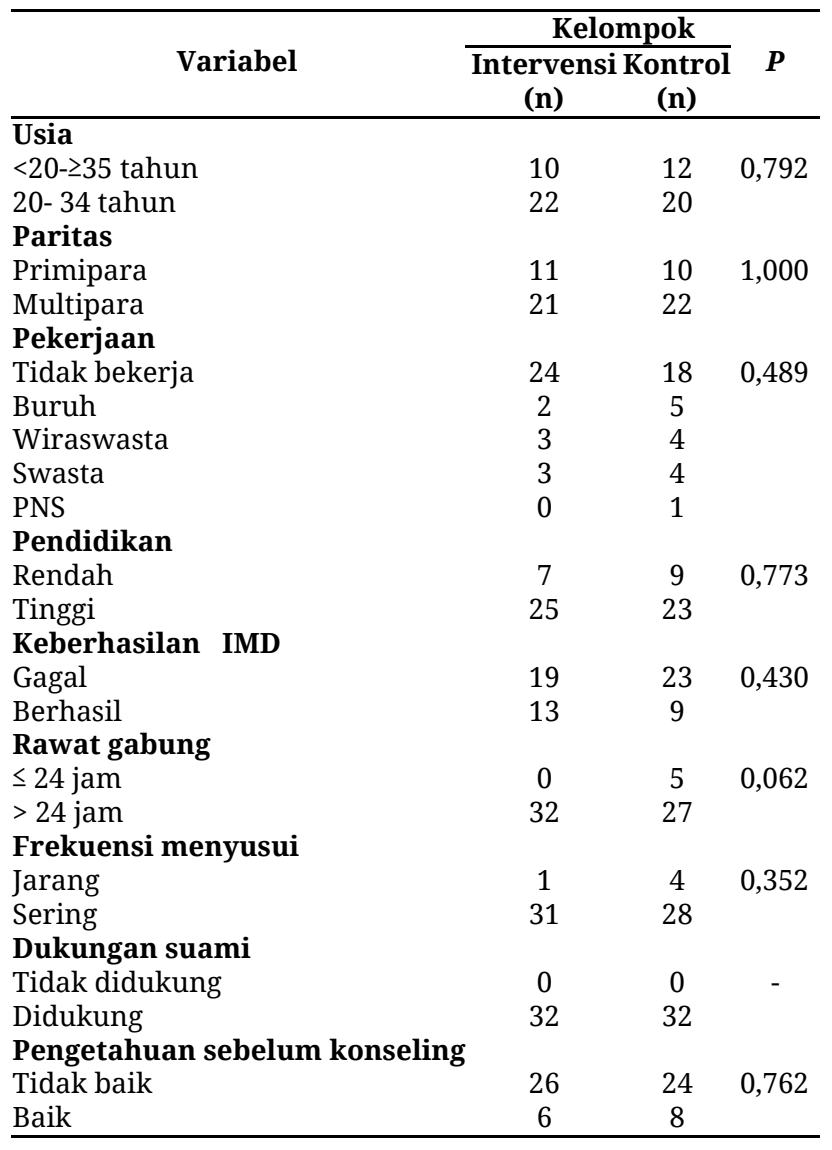

Pada tabel 2 dan 3 terlihat bahwa pada kelompok intervensi terdapat perubahan pengetahuan yang signifikan setelah diberikan konseling ( $p$-value $0,000<0,05)$, sedangkan pada kelompok kontrol sebalik- nya ( $p$-value 0,500>0,05). Adapun hasil uji beda kedua kelompok didapatkan tidak ada perbedaan pengetahuan yang signifikan antara kelompok intervensi dengan kelompok kontrol sebelum diberikan konseling ( $p$ value 0,762>0,05; RR 0,923), hal ini berbeda dengan analisis data setelah diberikan konseling ( $p$ value $0,000<0,05$; RR 11,000).

Tabel 2. Pengaruh konseling laktasi terhadap pengetahuan ibu dalam pemberian ASI

\begin{tabular}{|c|c|c|c|c|c|}
\hline \multirow{3}{*}{ Pengetahuan } & \multicolumn{2}{|c|}{ Pre } & \multicolumn{2}{|c|}{ Post } & \multirow{3}{*}{$\begin{array}{c}\text { P-value } \\
\text { Pre- } \\
\text { Post }\end{array}$} \\
\hline & $\begin{array}{c}\text { Tidak } \\
\text { Baik }\end{array}$ & Baik & $\begin{array}{l}\text { Tidak } \\
\text { Baik }\end{array}$ & Baik & \\
\hline & $\begin{array}{c}n \\
(50)\end{array}$ & $\begin{array}{c}n \\
(14)\end{array}$ & $\begin{array}{c}n \\
(24)\end{array}$ & $\begin{array}{c}n \\
(40)\end{array}$ & \\
\hline Kontrol & 24 & 8 & 22 & 10 & 0,500 \\
\hline Intervensi & 26 & 6 & 2 & 30 & 0,000 \\
\hline
\end{tabular}

Tabel 3. Perbedaan pengetahuan sebelum dan sesudah dilakukan konseling

\begin{tabular}{lcccc}
\hline \multirow{2}{*}{ Pengetahuan } & Kontrol & Intervensi & \multirow{2}{*}{ P-Value } & RR \\
\cline { 2 - 3 } & $\mathbf{n}$ & $\mathbf{n}$ & & \\
\hline Sebelum & & & & \\
Tidak Baik & 24 & 26 & & 0,92 \\
Baik & 8 & 6 & 0,762 & 3 \\
Total & 32 & 32 & & \\
Sesudah & & & & \\
Tidak Baik & 22 & 2 & & 11,0 \\
Baik & 10 & 30 & 0,000 & 00 \\
Total & 32 & 32 & & \\
\hline
\end{tabular}

Pada Tabel 4 terlihat bahwa terdapat perbedaan kemampuan menyusui yang signifikan antara kelompok intervensi dengan kelompok kontrol setelah diberikan konseling laktasi ( $p$-value 0,012<0,05; $\mathrm{RR}$ 1,917). Pada kelompok intervensi sebanyak 20 responden yang mampu dalam pemberian ASI sedangkan pada kelompok kontrol hanya 9 responden.

Tabel 4. Pengaruh konseling laktasi terhadap kemampuan ibu dalam pemberian ASI

\begin{tabular}{|c|c|c|c|c|c|c|c|c|}
\hline \multirow{2}{*}{$\begin{array}{l}\text { Kemampuan } \\
\text { Menyusui }\end{array}$} & \multicolumn{2}{|c|}{ Tidak Mampu } & \multicolumn{2}{|c|}{ Mampu } & \multicolumn{2}{|c|}{ Total } & \multirow{2}{*}{ P-value } & \multirow{2}{*}{$\mathbf{R R}$} \\
\hline & $\mathbf{n}$ & $\%$ & $\mathbf{n}$ & $\%$ & $\mathbf{n}$ & $\%$ & & \\
\hline Kontrol & 23 & 71,9 & 9 & 28,1 & 32 & 100,0 & \multirow{3}{*}{0,012} & \multirow{3}{*}{1,917} \\
\hline Intervensi & 12 & 37,5 & 20 & 62,5 & 32 & 100,0 & & \\
\hline Total & 35 & 54,7 & 29 & 45,3 & 64 & 100,0 & & \\
\hline
\end{tabular}

Tabel 5 menunjukkan terdapat perbedaan keberhasilan ASI eksklusif yang signifikan antara kelompok intervensi dengan kelompok kontrol setelah diberikan konseling ( $p$ value 0,006<0,05; RR 2,500). Keberhasilan dalam pemberian ASI pada kelompok intervensi sebanyak 24 responden, sedangkan pada kel- ompok kontrol sebanyak 12 responden. Keberhasilan dalam pemberian ASI dipengaruhi adanya dukungan keluarga, informasi yang jelas dari profesi atau tenaga kesehatan. Pendidikan ibu dan keluarga, nutrisi yang adekuat juga akan memengaruhi proses dalam menyusui

Tabel 5. Pengaruh konseling laktasi terhadap keberhasilan ibu dalam pemberian ASI

\begin{tabular}{lccccccc}
\hline Keberhasilan & \multicolumn{2}{c}{ Tidak Berhasil } & \multicolumn{2}{c}{ Berhasil } & \multicolumn{2}{c}{ Total } & \multirow{2}{*}{$\boldsymbol{P}$-value } \\
\cline { 2 - 7 } ASI Eksklusif & $\mathbf{n}$ & $\mathbf{0}$ & $\mathbf{n}$ & $\mathbf{\%}$ & $\mathbf{n}$ & 100,0 \\
\hline Kontrol & 20 & 62,5 & 12 & 37,5 & 32 & 0,006 \\
Intervensi & 8 & 25,0 & 24 & 75,0 & 32 & 100,0 \\
Total & 28 & 43,8 & 36 & 56,3 & 64 & 100,0 \\
\hline
\end{tabular}




\section{BAHASAN}

Karakteristik yang dilihat dalam penelitian ini adalah usia ibu, paritas, pekerjaan, pendidikan, keberhasilan IMD, rawat gabung, frekuensi menyusui dan dukungan suami. Karakteristik umur responden menunjukkan bahwa responden yang terlibat dalam intervensi maupun kontrol sebagian besar berusia 20-34 tahun. Usia sangat menentukan kondisi maternal dan berkaitan dengan kondisi kehamilan, persalinan dan menyusui (7).

Pengetahuan ibu yang baik berpeluang meningkatkan pemberian ASI eksklusif. Pengetahuan ibu tentang pentingnya menyusui akan meningkat jika selama masa kehamilan dan proses persalinan mendapatkan informasi dan dukungan yang adekuat. Hal ini sejalan dengan penelitian yang dilakukan yang menunjukkan bahwa pengetahuan kelompok yang mendapat konseling laktasi intensif lebih tinggi dibanding kelompok kontrol. Peningkatan pengetahuan disebabkan karena konseling yang menempatkan ibu sebagai subjek, bukan sebagai objek akan menaruh minat yang besar untuk mengikuti konseling (8).

Intensitas konseling juga merupakan faktor yang memengaruhi peningkatan pengetahuan ibu, sehingga makin sering terjadi kontak antara ibu dan konselor maka makin sering ibu mendapatkan informasi, yang secara tidak langsung meningkatkan pengetahuan ibu. Manfaat lain dari intensitas konseling yang sering adalah proses pengulangan informasi yang menjadi faktor pendukung dalam pemahaman ibu terhadap informasi tersebut. Informasi atau pengetahuan yang sering dan berulang-ulang dapat meningkatkan retensi pengetahuan seseorang (9).

Diperlukan pengetahuan terkait teknik menyusui dengan benar untuk mencapai keberhasilan menyusui. Seorang ibu membutuhkan seseorang yang dapat membimbing dalam merawat bayi termasuk dalam menyusui (10). Sosok yang dapat membantu adalah orang yang berpengaruh atau disegani seperti suami, keluarga, kerabat, kelompok ibu pendukung ASI dan tenaga kesehatan.

Masalah yang banyak dialami oleh ibu adalah ketidakmampuan ibu terkait cara perlekatan yang benar, sehingga masalah yang banyak dialami oleh ibu pada penelitian ini adalah puting lecet, jumlah ASI yang sedikit dan bayi rewel. Agar proses menyusui berjalan dengan lancar, maka seorang ibu harus mempunyai keterampilan menyusui agar ASI dapat mengalir dari payudara ibu ke bayi secara efektif. Keterampilan menyusui yang baik meliputi posisi menyusui dan perlekatan bayi pada payudara yang tepat. Perlekatan yang tepat hanya dapat dilakukan jika posisi juga sudah tepat. Kunci keberhasilan perlekatan bayi adalah posisi badan bayi dan ibu sudah sesuai, yaitu seluruh badan bayi mengahdap ke badan ibu.

Salah satu upaya peningkatan pemberian ASI eksklusif dapat dilakukan melalui kegiatan promosi dengan cara penyuluhan dan konseling pemberian ASI sejak dini kepada ibu hamil, terutama ibu hamil trimester ketiga, agar ibu lebih siap memberikan ASI sedini mungkin tanpa memberikan makanan ataupun minuman prelaktal. Hasil penelitian ini menunjukkan, ibu yang berhasil memberikan ASI saja tanpa makanan tambahan lain selama 1 minggu setelah melahirkan adalah ibu yang mendapatkan dukungan penuh dari keluarga, terutama suami. Hal ini sejalan dengan penelitian lain yang menyebutkan bahwa lingkungan rumah juga memengaruhi keberhasilan pemberian ASI eksklusif (11). Peran keluarga dalam mendukung ibu agar tetap memberikan ASI sampai usia 6 bulan sangat penting. Jika hanya ibu yang memiliki niat untuk memberikan ASI tanpa dukungan keluarga keberhasilan pemberian ASI tidak akan berhasil.

Disimpulkan bahwa konseling laktasi kepada ibu hamil trimester ke-3 memengaruhi keberhasilan ibu dalam pemberian ASI dan dapat memengaruhi ibu secara signifikan pada 1 minggu setelah melahirkan. Konseling prenatal memiliki dampak terhadap pemberian ASI sampai 4-6 minggu, sedangkan konseling yang diberikan pada saat pranatal dan postnatal berpengaruh terhadap pemberian ASI eksklusif sampai dengan 6 bulan (12).

\section{SIMPULAN}

Terdapat perbedaan pengetahuan yang signifikan pada kelompok intervensi setelah diberikan konseling laktasi, sedangkan pada kelompok kontrol tidak terjadi perubahan pengetahuan yang signifikan. Hasil penelitian menunjukkan pengetahuan pada kelompok intervensi lebih tinggi setelah dilakukan konseling laktasi dibandingkan dengan kelompok kontrol. Terdapat perbedaan kemampuan menyusui yang signifikan antara kelompok intervensi dengan kelompok kontrol setelah diberikan konseling laktasi dan terdapat perbedaan keberhasilan yang signifikan dalam pemberian ASI antara kelompok intervensi dengan kelompok kontrol setelah diberikan konseling laktasi. 


\begin{abstract}
Abstrak
Tujuan: Penelitian ini bertujuan untuk mengetahui pengaruh konseling laktasi terhadap pengetahuan, kemampuan dan keberhasilan ibu dalam pemberian ASI di RSUD Panembahan Senopati Bantul. Metode: Desain penelitian yang digunakan adalah "quasi experiment with post test-only non equivalent control group design". Teknik pengambilan sampel dengan consecutive sampling dengan jumlah sampel sebanyak 32 responden pada masing-masing kelompok (kelompok kontrol dan kelompok intervensi). Analisis bivariat menggunakan chi square dengan tingkat kemaknaan $\mathrm{p}<0,05$. Hasil: Hasil penelitian menunjukkan adanya perbedaan pengetahuan yang signifikan setelah dilakukan konseling laktasi pada kelompok intervensi ( $p$ value $0,000<0,05$ ), terdapat perbedaan kemampuan menyusui yang signifikan antara kelompok intervensi dengan kelompok kontrol setelah diberikan konseling laktasi ( $p$ value $0.012<0.05$; RR 1.917) dan terdapat perbedaan keberhasilan dalam pemberian ASI yang signifikan antara kelompok intervensi dengan kelompok kontrol setelah diberikan konseling ( $p$ value 0,006 $<0,05$; RR 2,500). Simpulan: Konseling laktasi berpengaruh terhadap pengetahuan, kemampuan dan keberhasilan ibu dalam pemberian ASI.
\end{abstract}

Kata kunci: konseling; laktasi; pemberian ASI

\section{PUSTAKA}

1. Roesli U, Yohmi E. Manajemen laktasi. Jakarta: IDAI. 2009.

2. Survei Demografi Kesehatan Indonesia (SDKI). AKI dan AKB tahun 2012 Menurut SDKI. 2012. http://pdfpath.com/pdf/.html. Diakses tanggal 26 Desember 2014.

3. Riskesdas. Rencana Kerja Pembinaan Gizi Masyarakat Tahun 2013. Jakarta: Direktorat Bina Gizi Kemenkes RI. 2013.

4. Dinas Kesehatan Provinsi Daerah Istimewa Yogyakarta. Profil Kesehatan Provinsi Daerah Istimewa Yogyakarta. 2013.

5. Dinkes Kabupaten Bantul. Profil Kesehatan Kabupaten Bantul. 2012.

6. Departemen Kesehatan RI. Pedoman Penyelenggaraan Pelatihan Konseling Menyusui Dan Pelatihan Fasilitator Konseling Menyusui, Jakarta. 2007.

7. Handayani, E. Trauma Kehamilan dan Pengaruhnya pada Janin. 2007. Di akses tanggal 11 Agustus 2015.

8. Ambarwati, R. Pengaruh konseling laktasi intensif terhadap pemberian air susu ibu (ASI) eksklusif sampai 3 bulan. Tesis. Jurnal Gizi Indonesia. 2013 Vol. 2, No. 1. Desember 2013: 15-23.

9. Notoatmodjo, S. Pendidikan dan Perilaku Kesehatan. Rineka Cipta. Jakarta. 2003.

10. Soetjiningsih. Masalah-masalah yang sering terjadi pada masa menyusui. dalam Soetjiningsih. (1997). ASI, petunjuk untuk tenaga kesehatan. EGC. Jakarta. 1997.

11. Hector D, King L, Webb K, Heywood P. Factors affecting breastfeeding practices. Applying a conceptual framework. New South Wales public health bulletin. 2005;16(4):52-5.

12. Imdad A, Yakoob MY, Bhutta ZA. Effect of breastfeeding promotion interventions on breastfeeding rates, with special focus on developing countries. BMC public health. 2011 Dec;11(3):S24. 
